\title{
Cibenzoline Therapy for Mitral Regurgitation in Patients with HOCM
}

Key words: hypertrophic obstructive cardiomyopathy, mitral regurgitation, cibenzoline

There are two types of hypertrophic cardiomyopathy (HCM): hypertrophic obstructive cardiomyopathy (HOCM) and hypertrophic non-obstructive cardiomyopathy. It is also known that there are two types of HOCM; obstruction at the subaorta, called idiopathic hypertrophic subaortic stenosis (IHSS), and obstruction at the mid left ventricle $(1,2)$. Unlike in patients with IHSS, systolic murmur in patients with midventricular obstruction is generally not loud, and specific markers, such as systolic anterior motion of the mitral valve and a spike-and-dome pattern on carotid pulse tracing are not found. Thus, in the clinical setting, patients with midventricular obstruction may often be overlooked. Mitral regurgitation associated with systolic anterior motion of the anterior leaflet of the mitral valve usually exists in most patients with IHSS, and its severity is known to be correlated with the severity of left ventricular pressure gradient (LVPG). A recent study elucidated that LVPG observed in patients with HOCM was related to the prognosis in patients with HCM (3). Therefore, it is an important strategy to attenuate LVPG and to decrease mitral regurgitation in patients with HOCM, especially in patients with IHSS. However, both $\beta$-blockers and calcium antagonists are often insufficient for attenuating LVPG. In 1982, Pollick (4) reported the usefulness of the antiarrhythmic drug disopyramide in attenuating LVPG in IHSS. Unfortunately sustained use of disopyramide is difficult owing to thirst, dysuria due to its strong anticholinergic action. We previously reported the usefulness of the antiarrhythmic drug, cibenzoline, the anticholinergic action of which is very weak, to attenuate LVPG and to improve left ventyricular diastolic functions in IHSS (5).

A manuscript in this journal by Inada et al (6) reported a patient with IHSS whose severe LVPG and mitral regurgitation disappeared by an intravenous administration of cibenzoline.

See also p 55.

Takada et al (7) also reported the same effect of intravenous administration of cibenzoline on LVPG and mitral regurgitation in a patient with IHSS. We can estimate at least two mechanisms for these beneficial effects of cibenzoline on hemodynamics in patients with IHSS. One mechanism for these effects is the negative inotropic action by cibenzoline (5). This negative inotropic action of cibenzoline may be related to the suppression of left ventricular systolic function as reflected by a decrease of fractional shortening and by an increase of left ventricular end-systolic dimension. The other mechanism is the direct effect of cibenzoline through a marked decrease in the intracellular $\mathrm{Ca}^{2+}$ concentration of myocytes through $\mathrm{Na}^{+}$and $\mathrm{Ca}^{2+}$ channel blocking actions of cibenzoline (8). We indicated that left ventricular diastolic dysfunctions estimated by the transmitral Doppler flow pattern, left ventricular wall motion, apex cardiography and gated radionuclide angiography were all improved after the treatment by cibenzoline even in hypertrophic nonobstructive cardiomyopathy (9). This is the reason why we believe that cibenzoline could improve left ventricular diastolic dysfunction in patients with HCM through its direct effect.

Other recent studies have shown that the altered $\mathrm{Ca}^{2+}$ handling is related to sarcomeric disorganization in patients with HCM (10), and hypertrophic stimuli acting at the cell membrane leads to the elevation of intracellular $\mathrm{Ca}^{2+}$ and activation of calcineurin in the cytoplasm; both of these changes are closely related to myocardial hypertrophy (11) Intracellular $\mathrm{Ca}^{2+}$ overload is also known to be closely related to diastolic dysfunction in HCM (12). In view of these findings, the decrease in LVPG and mitral regurgitation may be closely related to the marked reduction of intracellular $\mathrm{Ca}^{2+}$ due to cibenzoline as mentioned above.

$$
\begin{array}{r}
\text { Mareomi HAMADA, MD } \\
\text { Division of Cardiology, Uwajima City Hospital, } \\
\text { 1-1 Goten-Machi, Uwajima, Ehime 798-8510 }
\end{array}
$$

\section{References}

1) Falicov RE, Resnekov L, Bharati S, Lev M. Mid-ventricular obstruction: a variant of obstructive cardiomyopathy. Am J Cardiol 37: 432437, 1976.

2) Hamada M, Shigematsu Y, Ohshima K, et al. Diagnostic usefulness of carotid pulse tracing in patients with hypertrophic obstructive cardiomyopathy due to midventricular obstruction. A comparison with idiopathic hypertrophic subaortic stenosis. CHEST 124: 1275-1283, 2003.

3) Maron BJ, Casey SA, Poliac LC, Gohman TE, Almquist AK, Aeppli DM. Clinical course of hypertrophic cardiomyopathy in a regional United States cohort. JAMA 281: 650-655, 1999 (Erratum in: JAMA 
281: 2288, 1999).

4) Pollick C. Muscular subaortic stenosis. Hemodynamic and clinical improvement after disopyramide. N Engl J Med 307: 997-999, 1982.

5) Hamada M, Shigematsu Y, Ikeda S, et al. Class Ia antiarrhythmic drug cibenzoline. A new approach to the medical treatment of hypertrophic obstructive cardiomyopathy. Circulation 96: 1520-1524, 1997.

6) Inada K, Komukai K, Mori C, Nagasawa H, Shibata T, Mochizuki S. Mitral regurgitation disappearance after cibenzoline treatment in a patient with hypertrophic obstructive cardiomyopathy. Intern Med 43: 55-58, 2004.

7) Takada Y, Suesada H, Shudou K, et al. A case of hypertrophic obstructive cardiomyopathy with marked reduction in left ventricular pressure gradient with cibenzoline. Shinzou 33: 531-536, 2001 (in Japanese).

8) Holck M, Osterrieder W. Inhibition of the myocardial $\mathrm{Ca}^{2+}$ inward current by the class I antiarrhythmic agent, cibenzoline. Br J Pharmacol
87: 705-711, 1986.

9) Hamada M, Shigematsu Y, Hara Y, et al. Antiarrhythmic drug, cibenzoline, can directly improve the left ventricular diastolic function in patients with hypertrophic cardiomyopathy. Jpn Circ J 65: 531-538, 2001.

10) Palmiter KA, Solaro RJ. Molecular mechanisms regulating the myofilament response to $\mathrm{Ca}^{2+}$ : implications of mutations causal for familial hypertrophic cardiomyopathy. Basic Res Cardiol 92: 63-74, 1997.

11) Molkentin JD, Lu J-R, Antos CL, et al. A calcineurin-dependent transcriptional pathway for cardiac hypertrophy. Cell 93: 215-228, 1998.

12) Gwathmey JK, Warren SE, Briggs GM, et al. Diastolic dysfunction in hypertrophic cardiomyopathy. Effect on active force generation during systole. J Clin Invest 87: 1023-1031, 1991. 